\title{
Chemical and immunological testing for faecal occult blood in screening subjects at risk of familial colorectal cancer
}

\author{
L M Hunt, P S Rooney, K Bostock, M H E Robinson, J D Hardcastle, N C Armitage
}

\begin{abstract}
Background-People with a family history of colorectal cancer have an increased risk of the disease themselves. Many centres are advocating family history screening by endoscopy.

Aims-The performance of chemical and immunological faecal occult blood tests (Haemoccult and Hemeselect) in 212 subjects with a family history of colorectal cancer was assessed.

Results-Both Hemeselect and Haemoccult were positive in the only patient with colorectal cancer. Hemeselect was more sensitive than Haemoccult for adenomas (40\% compared with $20 \%$ ) (adenomas larger than $1 \mathrm{~cm} 75 \%$ compared with $50 \%$ ). No additional abnormality was detected by the addition of Haemoccult or Hemeselect to $60 \mathrm{~cm}$ flexible sigmoidoscopy in screening people at lower levels of familial risk. A false positive rate of $16 \%$ for Hemeselect resulted in a high proportion of additional colonoscopies in this group. Conclusions-At present faecal occult blood tests are not sufficiently sensitive or specific to replace endoscopy in screening people at risk of familial colorectal cancer. (Gut 1997; 40: 110-112)
\end{abstract}

Keywords: faecal occult blood tests, colorectal cancer.

The guaiac based Haemoccult (HO) (Rohm Pharma) has been widely investigated in mass population screening studies. It is cheap, simple, and quick to use. It has a sensitivity of $50-65 \%$ for asymptomatic colorectal cancer ${ }^{1}{ }^{2}$ and $33 \%$ for large adenomas. ${ }^{3}$ Its sensitivity is lowest in the rectum and caecum. ${ }^{12}$ Sensitivity can be increased by rehydration, but this also increases the false positive rate from $1-2 \%$ to $6-10 \%{ }^{45}$

Immunological faecal occult blood tests (FOBT) are highly specific for human haemoglobin, offering the prospect of greater sensitivity without loss of specificity. In symptomatic patients, HemeSelect (HS) (Smith-Kline Diagnostics) has a sensitivity for cancer of $94 \%$, and adenomas larger than $1 \mathrm{~cm}$ of $67 \%$. However, increased sensitivity is accompanied by some loss of specificity when compared with HO (84\% compared with $96 \%){ }^{3}$ High risk groups, such as those with a family history of colorectal cancer, are currently screened by colonoscopy when the risk is very high; for example, hereditary non-polyposis colorectal cancer (HNPCC) but by flexible sigmoidoscopy or FOBT for lesser degrees of risk. We wished to investigate the sensitivity and specificity of HemeSelect in a group at high risk undergoing colonoscopy and the effect of adding HS to flexible sigmoidoscopy in people at lesser risk.

\section{Methods}

\section{PATIENTS}

$\mathrm{HO}$ and HS were examined in two groups of subjects, detailed below. Subjects were asked to complete $\mathrm{HO}$ and $\mathrm{HS}$ tests on each of three daily bowel motions before endoscopy. Rehydration of $\mathrm{HO}$ test cards was not performed. A blue discolouration at 30 seconds was taken as a positive reaction after the application of two drops of $1 \% \mathrm{w} / \mathrm{w}$ hydrogen peroxide. ${ }^{3}$ Erythrocyte agglutination at a $1: 8$ dilution was taken as a positive reaction for HS. $^{3}$ No dietary restriction was enforced. Participants were recruited, to the study, from an open access clinic for relatives of colorectal cancer patients and a number of case finding initiatives ongoing in our unit. Overall compliance, with endoscopy was $73 \%$ at the time of study, but many people were self referring volunteers. The male:female ratio was 1:1.58. Subjects who presented with symptoms were excluded from analysis.

\section{Group 1}

A total of 125 people at high risk of familial colorectal cancer (two or more first degree relatives or first degree relative affected under the age of 50 years) had a colonoscopy, (plus completion barium enema in 19 patients) and completed $\mathrm{HO}$ and $\mathrm{HS}$ tests before examination. The mean age of those completing FOBT was 46 years (range 20-73; median 46). Of the 125 subjects completing all tests, 10 were found to have neoplasia. No cancers were found. Four subjects had adenomas larger than $1 \mathrm{~cm}$ (ages 18, 30, 44 and 46 years).

\section{Group 2}

A total of 87 people at lower levels of familial risk (single first degree, or first and second degree relative over the age of 50 years), scheduled for $60 \mathrm{~cm}$ flexible sigmoidoscopy completed both $\mathrm{HO}$ and $\mathrm{HS}$ tests. The mean age of those completing FOBT was 49 years (range 40-75; median 50). Neoplasia was 
detected in six (7\%) of these subjects. One person had cancer (age 67 years) and five had adenomas, two of whom had adenomas larger than $1 \mathrm{~cm}$ (ages 55 and 73 years).

\section{Results}

GROUP 1

\section{Haemoccult}

Four subjects $(3 \%)$ had a positive HO test. Two were true positive tests, colonoscopy revealing adenomas (both larger than $1 \mathrm{~cm}$ ) and two were false positive tests, colonoscopy revealing no abnormality. One hundred and twenty one subjects had negative $\mathrm{HO}$ tests, 113 $(91 \%)$ being true negative results and eight false results, adenomas being detected at colonoscopy. Two people with a false negative $\mathrm{HO}$ test had adenomas larger than $1 \mathrm{~cm}$.

The positive predictive value of $\mathrm{HO}$ in this group was $50 \%$ for adenomas greater than $1 \mathrm{~cm}$. The sensitivity was $20 \%$ for all adenomas and $50 \%$ for adenomas larger than $1 \mathrm{~cm}$. The specificity of $\mathrm{HO}$ was $98 \%$.

\section{HemeSelect}

Twenty one subjects (17\%) had a positive HS test and had a colonoscopy. Four were true positive tests, showing adenomas (three larger than $1 \mathrm{~cm}$ ) and 17 were false positive tests, with no abnormality. Some 104 subjects had negative HS tests, 98 (94\%) being true negative results and six false negative results, adenomas being detected at colonoscopy. Only one person with a false negative HS test had an adenoma larger than $1 \mathrm{~cm}$ found at colonoscopy.

The positive predictive value of $\mathrm{HS}$ in this group was $20 \%$ for adenomas greater than $1 \mathrm{~cm}$. The sensitivity was $40 \%$ for all adenomas and $75 \%$ for adenomas larger than $1 \mathrm{~cm}$. The specificity of HS was $86 \%$. Three subjects $(2 \cdot 4 \%)$ had positive $\mathrm{HO}$ and $\mathrm{HS}$ tests and all had adenomas (two larger than $1 \mathrm{~cm}$ ).

\section{Group 2}

Two subjects had positive HO test with a negative HS test, both were false positives. Twelve had a positive HS test with a negative $\mathrm{HO}$, only one being a true patient (patient with $1 \mathrm{~cm}$ rectal adenoma). Two subjects had positive $\mathrm{HO}$ and HS tests. One of these had a Dukes's stage B cancer of the sigmoid colon. In the other no colonic abnormality was found but the patient reported profuse epistaxis on several days immediately before and during completion of the tests. Four subjects with negative $\mathrm{HS}$ and $\mathrm{HO}$ tests had adenomas detected on flexible sigmoidoscopy. HO, HS, and flexible sigmoidoscopy were all negative in $67(77 \%)$ of subjects.

In this group, the positive predictive value of $\mathrm{HO}$ was $25 \%$ and HS $14 \%$. The sensitivity and specificity of the tests cannot be calculated in this cohort as most people did not undergo colonoscopy. Sixteen underwent colonoscopy because of a positive FOBT, 14 of whom had no abnormality detected. Two had neoplasia detected, both within reach of the $60 \mathrm{~cm}$ flexible sigmoidoscope, (one rectal and one sigmoid colon). Therefore, in this cohort no additional abnormality was detected by FOBT. The high false positive rate of HS (16\%) resulted in a large proportion of 'unnecessary' colonoscopies.

\section{Discussion}

First degree relatives of patients with colorectal cancer have a threefold to fourfold increased risk of developing the disease themselves. ${ }^{6-8}$ Screening studies have consistently shown relatives of colorectal cancer patients have more neoplasia than control populations ${ }^{9-12}$ and screening of familial colorectal cancer is widely recommended. ${ }^{14}$

There is debate over the screening modality of choice. ${ }^{14}$ The risk of colorectal cancer to which a person is subject is dependent upon the number and ages of affected relatives. 815 Most authorities feel that high risk subjects (two or more affected relatives or a first degree relative affected before the age of 45 years) should be screened by colonoscopy. ${ }^{16}$ Making screening recommendations for those at lower levels of risk (single older first degree relative with colorectal cancer) is difficult as much published screening data fails to give details of family risk and the age of those screened. Recommendations vary from full colonoscopy ${ }^{14}$ to FOBT with Haemoccult. ${ }^{13}$

Among people at high levels of familial risk, although the incidence of adenomas is not especially high, their rate of conversion to cancers may be significantly increased. ${ }^{17} \mathrm{~A}$ screening test for these people will therefore need to be sensitive for adenomas. Our study has confirmed other reports ${ }^{1013}$ that found Haemoccult is not sufficiently sensitive for familial colorectal cancer screening. We found HemeSelect to be more sensitive for adenomas in this group but associated with a higher false positive rate. Its performance in this group was similar to that in symptomatic patients. ${ }^{3}$

In people with lower levels of familial risk it has been suggested that FOBT may be a useful adjunct to left sided endoscopy in screening subjects at lower levels of familial risk. ${ }^{12}$ This has not been shown by our study, with no additional neoplasia being detected by the addition of $\mathrm{HO}$ and $\mathrm{HS}$ to $60 \mathrm{~cm}$ flexible sigmoidoscopy. Furthermore the high false positive rate of HS, and therefore high level of colonoscopy will add considerably to the cost of a screening programme using this test.

Detection of tumour associated antigens such as carcinoembryonic antigen ${ }^{18}$ or the protein products of tumour mutations potentially provide more specific markers, although mutant p53 has proved initially disappointing. ${ }^{19}$ Therefore at least for the present time there is no FOBT that appears sufficiently sensitive to replace endoscopy in screening people at risk of familial colorectal cancer.

L M Hunt was supported by a locally funded research grant from Trent Regional Health Authority. 
1 Kronborg O, Fenger C, Olsen J, Bech K Sondergaard O. Repeated screening for colorectal cancer with faecal occult blood test. A prospective randomised study at Funen, Denmark. Scand $\mathcal{f}$ Gastroenterol 1989; 24: 599-606.

2 Hardcastle JD, Thomas WM, Chamberlain J, Pye G Sheffield J, James $\mathrm{P}$, et al. Randomised controlled tria of faecal occult blood screening for colorectal cancer: results of the first 107,349 subjects. Lancet 1989; $1160-4$.

3 Thomas WM, Hardcastle JD, Jackson J, Pye G. Chemical and immunological testing for faecal occult blood: comparison of two tests in symptomatic patients. $\mathrm{Br} \mathcal{F}$ Cancer 1992

4 Kewenter J, Bjork S, Haglind E, Smith L, Svanvik J, Ahren C. Screening and rescreening for colorectal cancer: a controlled trial of faecal occult blood testing in 27700 subjects. Cancer 1988; 62: 645-51.

5 Mandel JS, Bond JH, Church TR, Snover DC, Bradley M, Schuman LM, Ederer F. Reducing mortality from colorectal cancer by screening for faecal occult blood. N Engl F Med 1993; 328: 1365-71.

6 Stephenson BM, Finan PJ, Gascoyne J, Garbett F, Murday VA, Bishop DT. Frequency of familial colorectal cancer. Br f Surgery 1991; 78: 1162-6.

7 Lovett E. Family studies in cancers of the colon and rectum. $B r 7$ Surgery 1976; 6: 13-8.

8 St John DJB, McDermott FT, Hopper JL, Debney EA, Johnson WR, Hughes ESR. Cancer risk in relatives of patients with common colorectal cancer. Ann Intern Med 1993; 118: 785-90

9 Cannon-Albright LA, Skolnick MH, Bishop DT, Lee RG, Burt RW. Common inheritance of susceptibility to colonic adenomatous polyps and associated colorectal cancers. N Engl f Med 1988; 319: 533-7.
10 Stephenson BM, Murday VA, Finan PJ, Quirke P, Dixon MF, Bishop DT. Feasibility of family based screening for colorectal neoplasia: experience in one general surgical practice. Gut 1993; 34: 96-100.

11 Guillem JG, Forde KA, Treat MR, Neugut AI, O'Toole KM, Diamond BE Colonoscopic screening for neoplasms in asymptomatic first degree relatives of colon cancer patients. Dis Colon Rectum 1992; 35: 523-9.

12 Rozen P, Fireman Z, Figer A, Legum C, Ron E, Lynch HT. Family history of colorectal cancer as a marker of potential malignancy within a screening program. Cancer 1987; 60: 248-54.

13 Houlston RS, Murday V, Haracopos C, Williams CB, Slack J. Screening and genetic counselling for relatives of patients with colorectal cancer in a family cancer clinic. BMF 1990; 301: 366-8.

14 Dunlop MG. Screening for large bowel neoplasms in individuals with a family history of colorectal cancer. $\mathrm{Br}$ 7 Surg 1992; 79: 488-94.

15 Slack J. Family cancer syndromes. $f(R$ Soc Med 1989; 82: 233-4.

16 UK Family Cancer Study Group. A policy document for the counselling and surveillance of colorectal cancer families. counselling and surveillance of colorec

17 Lynch HT, Smyrk TC, Watson P, et al. Genetics, natural history, tumor spectrum and pathology of hereditary non polyposis colorectal cancer: an updated review. Gastroenterology 1993; 104: 1535-49.

18 Stubbs RS, Nadkarni DM, Monsey HA. Faecal carcinoembryonic antigen in colorectal cancer patients. Gut 1986; 27: 901-5.

19 Robinson MHE, Durrant LG, Zehab R, Hardcastle JD. Identification of mutant $\mathrm{p} 53$ in the stool of patients with colorectal cancer (abstract). BrF Surg 1993; 80: 646. 